\title{
INTEGRASI THEOLOGIA SISTEMATIKA SECARA HOLISTIK
}

\author{
Oleh : Pdt. Dr. Pilipus Manggaprou, M.Th \\ Kepala SPMI
}

\begin{abstract}
$\underline{\text { ABSTRAK }}$
Secara praktis, bertolak dari arti "yadah" (PL) dan "ginosko" (PB), maka theologia adalah pengalaman: 1). "Mengenal Allah" melalui membaca dan merenungkan Alkitab; 2). "Bersekutu dengan Allah" secara intim (akrab) melalui komunikasi secara terbuka dan interaktif; 3). "Menjadi serupa dengan (character) Allah di dalam Tuhan Yesus" dalam segala hal; dan 4). "Melakukan kehendak Allah" dengan penuh ketaatan dan kesetiaan sebagai wujud pendeklarasian kemuliaan Allah.

Secara harafiah, theologia adalah istilah Yunani $\theta \varepsilon \circ \lambda$ o $\gamma 1 \alpha$ (Theo dan logia) yang diartikan sebagai ilmu yang mempelajari perkataanperkataan Allah. Perkataan-perkataan Allah itu diinspirasikan kepada para penulis dan diinskripturasikan ke dalam buku segala buku, yaitu Alkitab. Jadi obyek atau sumber theologia adalah Alkitab. Kalau Roh Kudus yang menginspirasikan para penulis mengenai perkataanperkataan Allah itu maka dipastikan bahwa apa yang disampaikan tidak mungkin salah, maka hanya Roh Kudus pula yang mengiluminasi para pembaca untuk mengerti perkataan-perkataan itu, bahkan hanya Roh Kudus yang mengaktifkan dan mengefektifkan para pembaca melakukan dan memberitakannya.

Suatu studi yang mempelajari hakikat theologia sistematika yang komprehensif dan integratif, yang dilatar-belakangi dan dilatar-depani oleh perubahan paradigma pemikiran theologia disepanjang sejarahnya dan dipengaruhi oleh perubahan era (dunia) modern kepada
\end{abstract}


postmodern yang menuntut upaya untuk membangun pemikiran dan penerapan theologia Kristen dengan semua bidang dalam rumpun studi theologia maupun dengan semua bidang disiplin ilmu non-theologia secara integratif.

Theologia adalah usaha manusia untuk mempelajari Alkitab dengan baik dan benar dengan tujuan agar manusia dapat mengenal Allah dan mengalami kebaikan serta kemurahan-Nya dan hidup sesuai dengan kehendak Allah dan hubungannya dengan sesama manusia serta semua ciptaan-Nya agar dapat menghasilkan perubahan pandangan hidup menuju kedewasaan sehingga mampu bertanggung jawab atas panggilan-Nya dalam melayani dengan tujuan untuk hormat dan kemuliaan-Nya saja.

\section{Kata Kunci : Integrasi, Teologi Sistematik, Holistik}

\section{A. PENDAHULUAN}

Suatu studi yang mempelajari hakikat theologia sistematika yang komprehensif dan integratif, yang dilatar-belakangi dan dilatar-depani oleh perubahan paradigma pemikiran theologia disepanjang sejarahnya dan dipengaruhi oleh perubahan era (dunia) modern kepada postmodern, yang menuntut upaya untuk membangun pemikiran dan penerapan theologia Kristen dengan semua bidang dalam rumpun studi theologia maupun dengan semua bidang disiplin ilmu non-theologia secara integratif sebagai buah dari studi integratif yang dapat disumbangsihkan dalam upaya mengatasi persoalan dunia, bangsa, gereja, keluarga dan pribadi Kristen.

\section{B. PENGERTIAN THEOLOGIA}

Secara harafiah, theologia adalah istilah Yunani $\theta \varepsilon \circ \lambda$ o $\gamma \mathbf{} \alpha$ (Theo dan logia) yang diartikan sebagai ilmu yang mempelajari perkataanperkataan Allah. Perkataan-perkataan Allah itu diinspirasikan kepada para penulis dan diinskripturasikan ke dalam buku segala buku, yaitu 
Alkitab. Jadi obyek atau sumber theologia adalah Alkitab. Kalau Roh Kudus yang menginspirasikan para penulis mengenai perkataanperkataan Allah itu, maka hanya Roh Kudus pula yang mengiluminasi para pembaca untuk mengerti perkataan-perkataan itu, bahkan hanya Roh Kudus yang mengaktifkan dan mengefektifkan para pembaca melakukan dan memberitakannya.

Secara teoritis, theologia adalah suatu aktivitas mempelajari Alkitab secara baik dan benar, merumuskannya, memeriksanya, mempertahankannya, dan mengkomunikasikannya kepada dunia melalui penginjilan dan kepada gereja melalui pengajaran. Dari definisi ini, maka theologia adalah: 1). Theologia adalah bersifat biblikal (mempelajari teks Alkitab secara benar); 2). Theologia bersifat sistematis dan komprehensif (merumuskan pemahaman iman secara sistematis dan menyeluruh); 3) Theologia bersifat historis (karena ia diformulasikan dari pengertian dan untuk pengertian konteks waktu dan ruang tertentu); 4). Theologia adalah bersifat kontemporer, yaitu kebenaran-kebenaran kekal yang dipahami dalam konteks masa kini. 5). Theologia bersifat praktis (how to teach, preach, counsel, evangelize).

Secara teoritis (semua orang Kristen/orang percaya), theologia adalah "suatu aktivitas iman orang percaya yang mempelajari Alkitab dengan maksud untuk mengalami kebaikan dan kemurahan Allah yang memungkinkannya setiap manusia dapat mengenal pribadi dan karyakarya-Nya dalam hubungannya dengan semua ciptaan-Nya yang ada di dalam dunia ini, khususnya manusia yang diciptkakan oleh Allah segambar dan serupa dengan Allah, dengan harapan terjadi perjumpaan dan persekutuan dengan-Nya yang menghasilkan perubahan world view dan kemajuan ke arah kedewasaan, sehingga dapat berespon secara bertanggung jawab terhadap panggilan-Nya, dengan kasih menjadi alat misi-Nya di dunia, demi kehendak-Nya terlaksana bagi kemuliaan-Nya saja."1

Dari definisi di atas, maka ada beberapa pokok pikiran yang patut ditegaskan, yaitu: 1). Theologia adalah usaha iman, pengharapan dan kasih. Dengan kata lain, yang belum percaya, tidak berpengharapan dan tanpa kasih tidak mungkin bertheologia. 2). Theologia adalah ibadah,

\footnotetext{
${ }^{1}$ Stevri Indra Lumintang, Keunikan Theologia Kristen di Tengah Kepalsuan Beriman, Beribadah, Beragama dan Berbangsa (Batu: Departemen Multimedia, Bidang Letaratur, 2010), hlm. 26.
} 
karena di dalam bertheologia terjadi pengalaman mengenal Allah, berjumpa serta bersekutu dengan-Nya. 3). Theologia adalah integratif, yaitu mempelajari relasi (hubungan) Allah dengan semua ciptaan (biologi, fisika, ekologi, sosiologi, anthropologi, psikologi dan lain sebagainya). 3). Theologia adalah pengalaman transformatif, yaitu perubahan mind-set (world view). 4). Theologia adalah proses menuju ke arah kedewasaan, karena hanya dalam kondisi demikian, orang Kristen (theolog) baru bisa bertanggung jawab dengan panggilan Tuhan atasnya. Panggilan Tuhan yang dimaksud adalah panggilan menjadi alat misi-Nya dalam dunia. Dengan demikian, theologia juga mengandung aspek misiologis. 5). Akhirnya, tujuan tertinggi theologia adalah menyatakan atau mendeklarasikan kemuliaan Allah. Semua pemikiran theologis menceritakan, menyatakan, memproklamasikan mengenai kemuliaan pribadi dan karya Allah.

\section{SEJARAH PERKEMBANGAN DAN PERUBAHAN PARADIGMA THEOLOGIA}

Kelahiran gereja pada peristiwa pentakosta, sebagaimana yang dilaporkan oleh Lukas dalam Kitab Kisah Para Rasul (atau Kisah Roh Kudus atau Kisah Gereja), merupakan permulaan pembentukan theologia Kristen. Karena itu, theologia gereja mula-mula selain menjadi titik tolak dan tolak ukur (standart) theologia gereja sepanjang sejarahnya. Sangatlah wajar sebagaimana yang sudah dan sedang terjadi, paradigma theologia terus berubah sesuai dengan tuntutan konteks waktu dan ruang, namun sangatlah disayangkan, perubahan paradigma theologia dari era ke era selalu dibarengi dengan pergeseran, sehingga semakin lama semakin menjauh dari standart theologia. Bersyukur, sekalipun terus terjadi pergeseran (penyimpangan), namun "benang merah theologia" yang ditarik lurus dari theologia gereja mula-mula tidak pernah putus. Itulah bukti providensi Roh Kudus atas gereja yang dilahirkan-Nya.

Sekali lagi, theologia Kristen bermula dari kelahiran gereja, Pertama: diformulasi dan dijadikan standart oleh dan dalam konteks gereja mula-mula; Kedua: dikembangkan dan direlevansikan oleh bapak-bapak gereja; Ketiga: diperkuat oleh Augustinus; Keempat diubah oleh theolog bagian pertama abad pertengahan; Kelima: dikotori 
dan diselewengkan oleh theolog kaum scholastic pada bagian kedua atau akhir abad pertengahan; Keenam: direformasi dan dipulihkan oleh theolog abad reformasi; Ketujuh: ditantang oleh filsuf, ilmuwan dan theolog abad modern abad ke-17 dan 18; Delapan: diselewengkan dan disangkal oleh theolog liberal/histories kritis abad ke-19; Sembilan: dicabut dan dikawinkan oleh theolog kontemporer abad ke-20; dan Sepuluh: sedang ditiadakan oleh theolog postmodern dan kaum pluralis pada abad ke-21 ini, dibuat di gereja-gereja Asia yang baru siuman dalam bertheologia.

Teologia tidak bisa dipisahkan dengan konteks. Ia bekerja bagi konteks dan bertanggungjawab bagi Allah. Teologia mengalami pasang surut karena tiga kemungkinan, pertama para pemimpin melakukan kesalahan dalam memahami teks dan ini berkaitan dengan kompetensi dirinya, yang bisa diakibatkan karena memiliki pengetahuan secara instan. Kedua para pemimpin melakukan kebohongan pengajaran, ini berkaitan dengan integritas dirinya, mungkin karena arus umat lebih kuat mempengaruhinya sehingga terjadi kompromi, kepalsuan dan kebohongan. Ketiga itulah kedaulatan Allah disetiap generasi dan abad. Perkembangan teologia bagaikan pohon zaitun yang kelihatan hampir mati namun selalu muncul tunas yang memberikan harapan dan kehidupan.

\section{PERUBAHAN DAN PERBEDAAN PARADIGMA THEOLOGIA MODERN DAN KONTEMPORER}

Terjadi perubahan theologi modern dan theologi kontemporer dikarenakan teologi modern lebih berpikir spesialis mendalam dan khusus serta dari teks, anologis, statis, tekstual, obyektif dan mengkotak-kotakkan teologi. Teologia kontenporer lebih memiliki pikiran luas dan mau tahu semua, dan dinamis, from below, konteks, dan subyektif. Teologia dunia pertama dan ketiga memiliki kelebihan dan kekurangannya masing-masing. Oleh sebap itu kedua theologia ini harus diintegrasikan agar kuat dan memiliki pikiran yang sistematik dan menyeluruh dalam melayani Allah dan sesama. 


\section{E. WILAYAH STUDI THEOLOGIA}

Sudah menjadi pengakuan bersama, bahwa studi theologia dibagi dalam lima wilayah studi, yakni: Pertama, theologia Biblika, yaitu studi yang bertalian dengan apa yang tertulis dalam Alkitab baik Perjanjian Lama dan Perjanjian Baru yang adalah firman Allah tanpa salah berdasarkan teks asli dan telah diilhamkan oleh Allah. Kedua, theologia Historika, yaitu studi yang mengetengahkan pengaruh dan pertumbuhan Firman Tuhan yang telah tercatat dalam sejarah. Ketiga, theologia sistematika, ialah studi yang mempelajari dan mempersoalkan apa yang harus dipegang sebagai dasar iman orang Kristen dari yang tertulis, yang telah diinterpretasikan, dirumuskan, dan diajarkan dalam komunitas Kristen. Keempat, theologia filosofika, yaitu studi yang terfokus pada upaya memproklamasikan, mempertahankan kebenaran dan menyerang kepalsuan berdasarkan Alkitab dan dengan pendekatan filosofis Kelima, theologia praktika, yaitu studi yang berhubungan dengan bagaimana cara menyampaikan Firman Allah yang tertulis itu dengan tepat, baik dan benar sehingga relevan dengan konteks manusia.

\section{F. TUGAS THEOLOGIA APOLOGETIC}

a. Allah ada, maka itu Allah dapat dikenal, sehingga ada jalan yang disediakannya untuk menusia mengenal-Nya

b. Bagaimana caranya mempertahankan kebenaran yang dipahami dan diimani?

\section{Tugas Theologia Biblikal}

a. Kebenaran tentang Allah diperoleh dari sumber primer mengenai informasi yang tersedia untuk kita, yang olehnya Allah dapat dikenal.

b. Bagaimana menemukan kebenaran dari teks? 


\section{Tugas Theologia Historika}

a. Kebenaran tentang Allah yang diperoleh dari sumber sekuder mengenai informasi yang tersedia dalam sejarah, yang olehnya Allah dapat dikenal.

b. Bagaimana menyadarkan kita mengenai pengaruh dalam kehidupan manusia dan lingkungannya?

\section{Tugas Theologia Praktika}

a. Kebenaran Allah yang diterapkan kepada manusia sesuai dengan kondisi dan kebutuhannya.

b. Bagaimana mempropagandakan kebenaran-kebenaran di dalam dunia?

\section{Tugas Theologia Sistematika}

a. Kebenaran Allah yang disuplai dari theologia apologetia, biblika, historika

b. Bagaimana memformulasi kebenaran-kebenaran dari materi apologetika, biblika, historika untuk kepentingan theologia praktika?

\section{G. EPISTEMOLOGI UMUM DAN THEOLOGIA KRISTEN}

Theologia, tentu bukanlah science, namun tidak bisa juga dikatakan bukan science. Tepatnya, theologia pada satu sisi adalah science, namun di sisi lain, theologia juga adalah meta-science. Setiap science, pasti memiliki dua faktor, yakni fakta dan ide, karena itu science adalah lebih dari pengetahuan. Theologia juga melampaui pengetahuan, namun tetap tidak bisa dipisahkan dengan pengetahuan. Karena itu, theologia pasti bertali-temali dengan epistemologi (cara memperoleh pengetahuan: How do you know what you know). Pada bagian berikut, penulis mengajak para pembaca untuk mencermati epistemologi para filsuf, dari Yunani Kuno, sampai filsuf modern, karena filsafat akar semua science, dan sangat kuat mempengaruhi theologia Kristen. 


\section{H. NATUR THEOLOGIA SISTEMATIKA}

Selain mencapai tujuan studi yang telah dikemukakan pada paragraf di atas, pembahasan berikut juga dapat melenyapkan mitosmitos mengenai topik theologia sistematika, diantaranya komentar theolog praktika, bahwa theologia sistematika adalah uraian dogmatis, akademis dan teoritis yang cenderung hanya berakhir di ruang kuliah atau ruang seminar, namun tidak nampak di tempat pemakaman, tidak terasa di saat orang kesakitan di rumah sakit, tidak muncul saat pasangan suami isteri berniat untuk bercerai, tidak terasa saat pohonpohon ditebang "seenaknya". Di sisi lain, theolog sistematika dengan bangga mengklaim bahwa karena kemampuan dan kesukaannya berpikir, maka theologia sistematika adalah pilihan tepat baginya. Begitu juga dengan komentar theolog biblika, dengan mengerutkan kening berkomentar mengenai keunggulan bidangnya dari bidang theologia sistematika, yang kemudian dibalas dengan arogan oleh theolog sistematika dengan pernyataan-pernyataan yang merendahkan theolog biblika. Mengapa demikian? Apakah memang demikian? Mari kita mulai pada diri kita. Dengan mempelajari hakikat theologia sistematika, mari kita tidak hanya mengenal Allah, melainkan juga mengenal profil theolog sistematika di antara theolog biblika, filosofika, historika, dan praktika.

\section{NAMA DAN PENGERTIAN THEOLOGIA SISTEMATIKA}

Ada dua istilah yang sering dipakai secara bergantian (interchangeably), yakni dogmatika dan theologia sistematika, karena adanya kesamaan yang mendasar. ${ }^{2}$ Namun, ada yang lebih memilih istilah dogmatika, seperti Herman Hoeksema. Beliau lebih memilih istilah dogmatika dari pada sistematika, karena alasannya, bahwa semua theologia, termasuk dogmatika, adalah sistematik, sebagaimana pada hakikatnya ilmu pengetahuan. Selain itu, baginya, dogmatika

\footnotetext{
${ }^{2}$ Semua ilmu pengetahuan, baik theologia maupun non-theologia, pasti harus menjadi sistematis dan scientific. Tidak terkecuali exegesis, it should be systematic and also scientific. Namun, patut ditegaskan di sini, bahwa sistematik theologia lebih dari dua indikasi itu.
} 
lebih sesuai dalam hubungannya dengan cabang ilmu theologia, sebagai rasa hormat kepada karya-karya gereja pada masa lampau. ${ }^{3}$ Itu berarti sangat bertali-temali dengan historika theologia. Namun, bagi penulis, istilah sistematika bukan hanya dalam pengertian pikiran yang tersusun secara sistematis, melainkan komprehensif, koheren, dan konsisten. Lebih dari itu, theologia sistematika adalah suatu sistem berpikir dan berkeyakinan. Benjamin B. Warfield menulis: "Systematic theology is not that it deals with its material in a systematic or methodical way, and other disciplines do not; but that it presents its material in the form of a system." 4

Jadi, sistematika theologia, lebih dari sekedar berpikir sistematik, melainkan berpikir dalam suatu sistem. Tentu, maksudnya adalah sistem berpikir theologis. Dengan demikian, theologia sistematika lebih luas dari dogmatika. Dengan kata lain, dogmatika adalah bagian dari sistematika theologia, sekalipun boleh saja disebut sebagai bagian utama, namun dogmatika pasti lebih bertalian dengan denominasi gereja tertentu, sedangkan theologia sistematika bersifat am. Selain semua itu, karena sifat kontemporer dan integratifnya, maka theologia sistematika lebih menjadi pilihan.

Dalam Teologi Sistematis bahan berkumpul di cabang-cabang sebelumnya diatur dalam urutan logis dan sedemikian rupa untuk menunjukkan hubungan satu sama lain dari berbagai doktrin iman Kristen, sehingga doktrin-doktrin iman dapat dilihat sebagailogis dan terhubung secara keseluruhan. Teologi Sistematik mencakup seluruh wilayah ajaran Kristen hampir bisa disebut suatu filsafat cabang life. Teologia Kristen bersumber dan melalui proses eksegese dan menghasilkan theologia biblical, dan teologia biblikal menghasilkan teologia sistematika, yang diperkaya dengan teologia historika dan selanjutnya menghasilkan teologia praktika. Misiologi tidak bisa berdiri sendiri karena merupakan muara dari teologia sistematika. Misiologi merupakan ranting dari teologia sistematika jadi apabila ranting mau dipisahkan, maka ia akan menjadi kering.

\footnotetext{
${ }^{3}$ Herman Hoeksema, Reformed Docmatics (Reformed Free Publishing Association), hlm. 3.

${ }^{4}$ Benjamin B. Warfield, Studies in Theology (Grand Rapids: Baker Book House, 2000), hlm. 49.
} 


\section{J. THEOLOGIA SISTEMATIKA YANG KOMPREHENSIF}

Sesuai dengan hakikatnya, bahwa theologia sistematika adalah bersifat komprehensif, demikian dengan panggilan bagi theolognya memiliki kemampuan menerima dan memiliki pengertian yang luas, lengkap dan koheren semua topik theologia sistematika.

\section{K. PRESUPOSISI STUDI KOMPREHENSIF}

a. Allah menyatakan Diri-Nya kepada manusia secara khusus dan lengkap melalui Firman-Nya (Alkitab) dan secara umum melalui ciptaan-Nya (Alam) dalam terang penyataan khusus. Alkitab adalah penyataan Allah yang lengkap. Dengan demikian, lengkapnya Alkitab sebagai acuan "membangun" theologia ke arah yang lengkap.

b. Alkitab bukan hanya penyataan Allah yang lengkap, melainkan juga penyataan Allah yang koheren. Seluruh kitab dan tulisan Alkitab bertali-temali satu dengan yang lain secara harmonis (baik antar kitab, maupun antar pokok pikirannya). Tidak ada kontradiksi di dalamnya, kecuali dalam pikiran manusia. Ini pun menjadi acuan studi theologia sistematika yang komprehensif.

Teologia sistematik yang komprehensif memperlihatkan kita bahwa bumi dan alam semesta hingga sorga dan neraka dikomunikasikan dan berada di dalam Alkitab yang adalah teologia itu sendiri, oleh sebab itu teologia sistematik itu harus bersifat konprehensif. Didalam Alkitab menjelaskan tentang pencipta dan seluruh yang diciptakan, dan itulah teologia yang lengkap.

\section{THEOLOGIA SISTEMATIKA YANG INTEGRATIF}

\section{Pengertian "Integratif"}

Integratif adalah kata sifat dari kata integrasi. Integrasi bukan dalam pengertian "peleburan" melainkan "terpadu secara sinergis dan harmonis." Kita meminjam pikiran integratif Charles Van Engen 
mengenai misi integratif untuk mengerti istilah "integrative," yaitu terpadunya biblical text, faith community dan missional context.

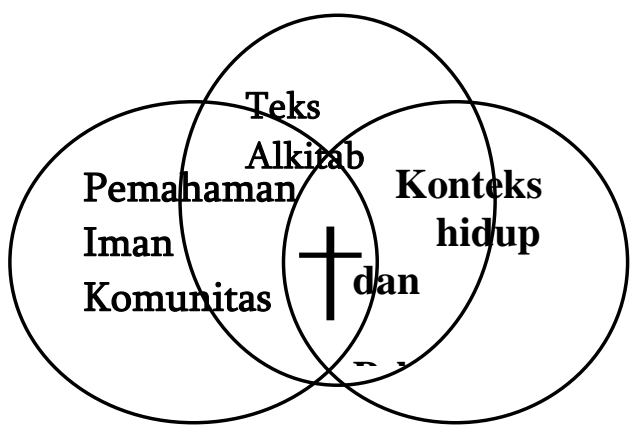

Teologia sistematik bersifat biblical, relevan, praktis dan komprehensif. Teologia sistematis yang integratif merupakan suatu keterpaduan yang harmonis dengan konteks dan dipertanggung jawabkan kepada Allah. Oleh sebab itu pengetahuan yang sistematis dan komprehensif tentang alam, manusia dan Allah sangat perlu agar dapat mengintegrasikan secara harmonis ke dalam masing-masing.

Sistem pemikiran yang integratif dan komprehensif merupakan usaha manusia untuk bersikap seperti Allah yang berpikir dan sumber dari komprehensif itu. Studi integrasi dapat membawa kita untuk melihat bahwa Allah berkarya pada semua disiplin ilmu pengetahuan dan kebenarannya hanya satu yaitu Allah itu sendiri.

\section{Integrasi Dalam Konteks Rumpun Theologia}

Theologia $\Longrightarrow\left\{\begin{array}{l}\text { Theologia Biblika } \\ \text { Theologia Historika } \\ \text { Theologia Sistematia } \Longrightarrow \\ \text { Theologia Filosofika } \\ \text { Theologia Praktika }\end{array} \quad\left\{\begin{array}{l}\text { Penyataan Allah } \\ \text { Allah } \\ \text { Manusia } \\ \text { Keselamatan } \\ \text { Gereja } \\ \text { Akhir Zaman }\end{array}\right.\right.$


Otoritas Alkitab bersumber pada otoritas Allah. Alkitab adalah penyataan khusus sedangkan ilmu pengetahuan adalah hasil penelitian dari penyataan umum sehingga terjadi pertentangan antara keduanya. Dalam perbedaan natur antara theologia dan ilmu pengetahuan dalam kedudukan dan wilayahnya masing-masing serta harmonisasi keduanya, maka dapat dikatakan "theologia adalah ratu ilmu pengetahuan dan ilmu pengetahuan adalah analisa theologi. Oleh sebab itu sikap wajar adalah menegaskan otoritas Alkitab atas ilmu pengetahuan dengan cara menempatkan ilmu pengetahuan di bawah kekuasaan theologia, karena orang percaya adalah mahluk ciptaan yang segambar dengan Allah dan yang menerima mandat untuk menguasai segala sesuatu termasuk menguasai ilmu pengetahuan, setelah diciptakan kembali di dalam Kristus oleh iman.

\section{Integrasi Dalam Konteks Non Theologia}

Integrasi theologia sistematika dengan disiplin ilmu non-theologia penting karena semua kebenaran adalah kebenaran Allah. Theologia dan Ekologi (Ecotheologia), Theologia dan Psikologi (Psychotheologia), Theologia dan Sosiologi (Sociotheologia), Theologia dan Politik (Politheologia), Theologia dan Ekonomi (Economitheologia), Theologia dan Anthropologi (Anthropotheologia), Theologia dan Biologi (Biotheologia), Theologia dan Fisika (Physicustheologia).

\section{DAFTAR PUSTAKA}

Alkitab. Lembaga Alkitab Indonesia, 2014.

Berkhof, Louis. Systematic Theology. Edinburgh: The Banner of Truth Trust, 1976.

Culver, Robert Duncan. Systematic Theology: Biblical and Historical. Geanies House, Ross-shire, Mentor Imprint, 2005.

Ebeling, Gerhard. The Study of Theology. London: Collin, 1979. 
Erickson, Millard, J. Reading in Christian Theology: Volume 1, The Living God. Grand Rapids: Baker Book House, 1992. 1994.

Where Is Theology Going? Grand Rapids: Baker Books,

Hodge, Charles. Systematic Theology, Volume One: Introduction, Part I, Theology. Grand Rapids: Wm. B. Eerdmans Publishing Company, 1989.

Hoeksema, Herman, Reformed Docmatics. Reformed Free Publishing Association, 1974.

Grudem, Wayne. Systematic Theology: An Introduction to Biblical Doctrine. Nottingham: Inter-Varsity Press, 1994.

Geisler, Norman. Systematic Theology: Introduction Bible. Minnesota: Bethany House, 2002.

Jinkins, Michael. Invitation to Theology: A Guide to Study, Conversation and Practice. Illinois: InterVaersity Press, 2001.

Kapic, M. Kelly. Mapping Modern Theology: A Thematic and Historical Introduction. Grand Rapids: Baker Academic, 2012.

Lumintang, Stevri I. Misiologia Kontemporer: Menuju Rekonstruksi Theologia Misi Seutuhnya, 2009.

Re-Indonesianisasi Bangsa. Batu: Departemen Multimedia YPPII Batu, 2009.

. Keunikan Theologia Kristen di Tengah Kepalsuan Beriman, Beribadah, Beragama dan Berbangsa. Batu: Departemen Multimedia POI, 2009.

MacArthurJohn, The Integrated Life: Sebuah Festschrift bagi Yakub dan Esther Susabda. Yogyakarta: PBMR ANDI, 2007.

Manalu, Parluhutan. "Memahami Theologia Dalam Surat Titus." SOTIRIA (Jurnal Theologia dan Pendidikan Agama Kristen) 2, no. 1 (2019): 39-59. http://sttpaulusmedan.ac.id/ejournal/index.php/sotiria/index. 